\title{
Early Obesity Prevention: A Randomized Trial of a Practice-Based Intervention in 0-24-Month Infants
}

\author{
Natalia Schroeder, ${ }^{1}$ Berenice Rushovich, ${ }^{2}$ Edward Bartlett, ${ }^{3}$ Sangita Sharma, \\ Joel Gittelsohn, ${ }^{1}$ and Benjamin Caballero' \\ ${ }^{1}$ Center for Human Nutrition, Bloomberg School of Public Health, Johns Hopkins University, Baltimore, MD 21205, USA \\ ${ }^{2}$ University of Maryland, School of Social Work, Ruth H. Young Center for Families and Children, Baltimore, MD 21201, USA \\ ${ }^{3}$ Johns Hopkins Community Physicians, Johns Hopkins Medicine, Baltimore, MD 21211, USA \\ ${ }^{4}$ Aboriginal and Global Health Research Group, Department of Medicine, Faculty of Medicine \& Dentistry, \\ University of Alberta, Edmonton, AB, Canada
}

Correspondence should be addressed to Benjamin Caballero; caballero@jhu.edu

Received 16 November 2014; Revised 21 April 2015; Accepted 22 April 2015

Academic Editor: Aron Weller

Copyright (c) 2015 Natalia Schroeder et al. This is an open access article distributed under the Creative Commons Attribution License, which permits unrestricted use, distribution, and reproduction in any medium, provided the original work is properly cited.

Objective. A pediatric office-based intervention was implemented following a randomized, controlled design, aimed at improving child feeding practices and growth patterns and ultimately reducing risk for overweight and obesity later in life. Methods. Four clinics (232 infants) were randomized to control or intervention (I), the latter delivered by health care provider at each of 7-9 wellbaby visits over 2 years, using a previously developed program (Growing Leaps and Bounds) that included verbal, visual, and text advice and information for parents. Results. The I group offered significantly less soda $(p=0.006)$, sweetened tea $(p=0.01)$, punch $(p=0.02)$ and/or cow's milk $(p=0.001)$ to infants and delayed the introduction of drink/food other than breast milk $(p<0.05)$. Parents in the I group had a higher perceived parental monitoring $(p=0.05)$ and restriction $(p=0.01)$ on infant feeding. While the I group exhibited at baseline more adverse socioeconomic indicators than the control group, growth trajectory or body size indices did not significantly differ between groups. Conclusions. Education provided by health care providers in addition to followup monthly phone calls may help modify parental behaviors related to child feeding and increase parental sense of responsibility toward child eating behaviors.

\section{Introduction}

Childhood obesity remains a major public health concern [1]. Approximately $17 \%$ of children and adolescents aged $2-$ 19 years are obese [1], and $9.7 \%$ of infants and toddlers (birth to 2 years) have high weight-for-recumbent length (95th percentile or higher) [2]. Excess weight during childhood may increase risk of noncommunicable diseases in adulthood [3].

Obesity prevention trials have largely focused on schoolchildren or adolescents. However, data from observational studies suggest that rapid growth in the first 2 years of age may be associated with higher risk of obesity later in life [4-6]. Therefore, this period needs to be studied to explore opportunities for early prevention interventions.
To the best of our knowledge, there are no previously randomized controlled educational interventions starting at birth and centered on the health care provider. The present study was designed to assess whether an early, office-based, scalable intervention could affect the usual pattern of feeding and growth trajectory over the first 2 years of life.

\section{Methods}

The study was a randomized, cluster-stratified clinical trial carried out in 4 health centers from the Johns Hopkins Community Physicians (JHCP) network in Maryland. Two centers were included in the intervention group and the other two in the control group. Centers were balanced to include 
one urban and one suburban center in each group. The study was completed when all participants reached 24 months of age.

Inclusion criteria included all healthy newborns with $\geq 2000 \mathrm{~g}$ body weight and who were not requiring specialized medical or nutritional care and discharged home within 5 days after birth. The intervention was based on the modules of Growing Leaps and Bounds (GLB), a set of educational materials developed by a group of experts and funded by the Dannon Institute. These materials aim at (a) promoting an exchange between patient and pediatrician about nutrition, feeding, and physical activity; (b) providing useful information to parents in order to enhance self-efficacy for the daily care of their infants; and (c) helping parents make healthy food choices for the infants and for themselves and make physical activity a part of daily life.

The 12 sets of educational brochures were designed to be presented and discussed with caregivers at pediatric visits at $1,2,4,6,9,12,15,18$, and 24 months of age and at annual visits thereafter up to age 5 years. While the brochures emphasize a few key points, they also provide detailed advice on infant feeding practices, physical activity, and developmental milestones related to eating patterns.

All participating pediatricians, nurse practitioners, and clinic staff attended training sessions before start of the study. Refresher sessions were held every 2-3 months. In the intervention clinics, the sessions focused on intervention content and delivery and in control clinics on the logistics and data collection. Participating pediatricians signed a memorandum of agreement and received a compensation of $\$ 150$ per infant enrolled.

All parents completed a brief exit interview after they saw the physician, as part of process evaluation data collection. In between visits, parents received a phone call every month, providing encouragement and answering questions. They also received reminder post cards which also contained short educational messages.

2.1. Anthropometry. Weight and height were measured in duplicate using Seca self-calibrating scales and Shorr stadiometers. Triceps and subscapular skinfolds were measured following the World Health Organization (WHO) protocol, using Lange calipers.

The scales used were self-calibrating and did not need additional calibration. All staff were trained on how to complete the various measurements and followed up with a gold standard check where one staff member completed a remeasure of the infant to check for agreement. This was completed approximately once a quarter. Two repeat measures were completed if the initial two measurements were more than a set amount apart.

2.2. Child Feeding Practices. We measured child feeding practices at 9 months, using an instrument developed for the Tips on Parenting Study (TOPS) (M. Black et al.) [7]. Parental control and restrictiveness were assessed using the Child Feeding Questionnaire (CFQ), at 12 and 24 months. The CFQ is a 31-item scale that examines caregivers' perceptions of their children's risk for weight and eating problems and caregiver control over feeding.

2.3. Dietary Assessment. We developed a Food Frequency Questionnaire (FFQ) specifically for this study. For this we performed a preliminary 24-hour dietary recall in a comparable population in Baltimore [8]. The FFQ was pilot-tested to identify foods that were consumed but were not reported in recalls, using a convenience sample of 16 participants, recruited from three of the four JHCP health care centers. Portion size was assessed using food models and familiar household utensils. Ten categories of frequency were used, ranging from "never" to "6 or more times per day" and covering the previous 30 days. FFQs were obtained at 6,12 , and 24 months, by trained, certified field staff.

2.4. Process Evaluation. Health care providers and study staff were evaluated on their compliance with intervention protocol and delivery of key intervention messages, including items such as delivery of the brochure to caregiver, discussion of front-page points of brochure, and reminder of key guidance items.

2.5. Data Analysis. All data collected in the field was entered into electronic files and verified by reentering every 10 th form by a staff other than the one collecting the data.

Data were analyzed using Stata statistics/data analysis software (version 11.2, College Station, Texas, 2009). Student's $t$-test was used to compare paired groups (intervention versus control, urban versus suburban). Analysis of variance (ANOVA) was used to determine differences among the four sites. Median height, weight, and BMI were used for trajectory plots. Linear regression models were used to determine the potential influence of SNAP participation on outcome variables. Covariates of interest included SNAP participation, WIC participation, breastfeeding, race, and gender. Significance was defined at the $p<0.05$ level.

\section{Results}

A total of 292 infants were enrolled and 232 completed the study. This was consistent with our predicted attrition rate of $20 \%$. All clinics but one had retention rates above $80 \%$. The clinic with low retention (67\%) near Washington, DC, serves many military families, which tend to be relocated frequently.

The breakdown of number of infants for each health center (included in the final analysis) was as follows: Center 1: 63 (31 M, 32 F); Center 2: 49 (18 M, 31 F); Center 3: 57 (31 M, 26 F); and Center 4: 53 (28 M, 25 F). Ethnicity breakdown for the JHCP health care centers (2005-2006) was as follows: Black $48 \%$, White $35 \%$, Asian 2\%, Hispanic 2\%, Indian 0\%, Multiracial 0\%, others 6\%, and unknown 7\%.

The intervention group had higher number of AfricanAmerican caregivers, higher unemployment rate, lower household income, lower completed education level, and less home ownership than the control group. The intervention group also used more food stamps and more WIC program 
TABLE 1: Anthropometric measurements of babies at baseline, 12 months, and final visit ${ }^{\mathrm{a}}$.

\begin{tabular}{|c|c|c|c|c|c|c|}
\hline & \multicolumn{2}{|c|}{ Baseline } & \multicolumn{2}{|c|}{12 months } & \multicolumn{2}{|c|}{ Final visit } \\
\hline & $\begin{array}{c}\text { Intervention } \\
n=134\end{array}$ & $\begin{array}{l}\text { Control } \\
n=144\end{array}$ & $\begin{array}{c}\text { Intervention } \\
n=105\end{array}$ & $\begin{array}{l}\text { Control } \\
n=113\end{array}$ & $\begin{array}{c}\text { Intervention } \\
n=112\end{array}$ & $\begin{array}{l}\text { Control } \\
n=110\end{array}$ \\
\hline & $\begin{array}{r}\text { Mear } \\
95 \% \text { confid }\end{array}$ & $\begin{array}{l}\text { SD) } \\
\text { ce interval }\end{array}$ & $\begin{array}{c}\text { Mean } \\
\text { 95\% confider }\end{array}$ & interval & $\begin{array}{r}\text { Mear } \\
95 \% \text { confid }\end{array}$ & D) interval \\
\hline \multirow{2}{*}{ BMI } & $15.29(1.53)$ & $15.03(1.58)$ & $17.23(1.58)$ & $17.29(1.95)$ & $16.34(1.59)$ & $16.20(1.25)$ \\
\hline & $15.04-15.56$ & $14.77-15.29$ & $16.93-17.54$ & 16.93-17.66 & $16.05-16.65$ & $15.96-16.44$ \\
\hline \multirow{2}{*}{ BMI $z$-scores } & $-0.283(0.96)$ & $-0.152(1.01)$ & $0.492(1.08)$ & $0.539(1.36)$ & $0.339(1.13)$ & $0.218(0.95)$ \\
\hline & $-0.45--0.12$ & $-0.32-0.01$ & $0.29-0.70$ & $0.29-0.79$ & $0.13-0.55$ & $0.04-0.40$ \\
\hline \multirow{2}{*}{ Weight (kg) } & $4.91(1.23)^{*}$ & $4.56(0.89)$ & 9.85 (1.11) & $9.81(1.29)$ & $12.76(1.63)$ & $12.61(1.47)$ \\
\hline & $4.71-5.13$ & $4.41-4.71$ & $9.64-10.07$ & $9.58-10.06$ & $12.46-13.07$ & $12.34-12.89$ \\
\hline \multirow{2}{*}{ Height (cm) } & $56.30(4.52)^{* *}$ & $54.81(3.10)$ & $75.53(2.49)$ & $75.31(3.06)$ & $88.20(3.21)$ & 88.13 \\
\hline & $55.53-57.07$ & 54.31-55.32 & $75.06-76.02$ & $74.74-75.88$ & $87.61-88.81$ & $87.54-88.73$ \\
\hline \multirow{2}{*}{ Triceps skinfold } & $7.94(2.28)$ & $7.85(2.58)$ & $9.70(2.09)^{* *}$ & $8.82(1.93)$ & $8.83(2.02)$ & $8.42(2.19)$ \\
\hline & $7.56-8.34$ & $7.43-8.28$ & $9.30-10.12$ & $8.44-9.20$ & $8.44-9.23$ & $7.97-8.87$ \\
\hline \multirow{2}{*}{ Triceps + subscapular skinfold } & $14.36(3.91)$ & $14.45(4.01)$ & $16.46(3.52)^{* * *}$ & $15.36(2.99)$ & $14.68(3.25)$ & $14.06(3.17)$ \\
\hline & $13.70-15.04$ & $13.78-15.12$ & $15.78-17.15$ & $14.78-15.95$ & $14.04-15.33$ & $13.40-14.72$ \\
\hline
\end{tabular}

${ }^{\text {a }}$ Student's $t$-test was used to compare intervention versus control at baseline, 12 months, and final visit.

${ }^{*} p<0.006,{ }^{* *} p<0.002$, and ${ }^{* * *} p<0.018$.

services and had lower rates of breastfeeding. These characteristics were particularly driven by the urban intervention clinic.

3.1. Implementation. Process evaluation was conducted to assess the quality of implementation of the intervention. Two primary measurement tools were developed, one to assess quality of implementation by pediatricians and the other by our study staff. Physicians and study staff received a score for each intervention visit based on whether they provided the appropriate brochure to the participant and how well they reinforced the key messages of the brochure. Physicians exhibited consistently lower implementation scores than study interventionists, and these scores decreased over time, from an average of about $70 \%$ to less than $50 \%$.

3.2. Impact on Anthropometry. Anthropometric data at baseline, 12 months, and final visit (24 months) is presented in Table 1. At 24 months of age, there was no effect of the intervention on height, weight, BMI, BMI $z$-scores, triceps skinfolds, or triceps + subscapular skinfolds. At baseline (1.42.0 months of age) weight and height were significantly higher in the intervention versus the control group $(p<0.006$ and $p<0.002$, resp.), but this difference disappeared at 12 and 24 months $(p>0.05)$. Triceps skinfold was higher in suburban clinics at 12 and 24 months but did not differ between intervention and control. A similar pattern was observed for the sum of triceps + subscapular skinfolds, although these results were only statistically significant at 12 months. All anthropometric results were similar when low birth weight $(<2500 \mathrm{~g})$ babies were excluded from the analyses.

Infant birth weight did not significantly differ between intervention and control (3251.7 g (565.02), 3220.8 g (480.72), resp.). However, infant birth weight significantly differed by clinic (EB 3191.8 $\mathrm{g}$ (460.13), OD $3318.0 \mathrm{~g}$ (660.58), WM $3358.7 \mathrm{~g}$ (483.72), and WP $3047.0 \mathrm{~g}(411.77)$ ) and if the location represented urban or suburban (3123.4 $\mathrm{g}$ (443.64), $3341.1 \mathrm{~g}$ (567.00), resp.) ( $p<0.0001)$. Additionally, white babies $(3338 \mathrm{~g})$ were significantly heavier than AfricanAmerican babies $(3107 \mathrm{~g})$ at birth $(p<0.004)$.

Growth trajectories for both weight and height were similar in intervention-control and urban-suburban clinics and closely tracked the medians of the 2006 WHO reference charts (see Figure 1).

Obesity prevalence in our sample was low $(0.6 \%$ to $0.4 \%$ for obesity and 3.8 to $4.3 \%$ for overweight at 6 and 24 months of age, resp.). Based on the Centers for Disease Control and Prevention (CDC) Growth Charts, if an infant was $>85 \%$ BMI percentile, the infant was considered overweight and if an infant was $>95 \%$ BMI percentile, then the infant was considered obese. The intervention group had a prevalence of overweight of 2.7 and $5.3 \%$ at 6 and 24 months, respectively. The control group had overweight prevalences of 4.7 and $3.2 \%$ at similar age periods. There was only one child classified as obese at the end of the study, in the intervention group.

3.3. Impact on Dietary Intake. The intervention group was less likely to use infant cereal $(p<0.001)$ or stage 1 vegetables $(p<0.05)$ as the first complementary food. Also, the intervention group offered significantly less soda $(p<0.006)$, sweetened tea $(p<0.01)$, punch $(p<0.02)$, or cow's milk $(p<0.001)$ than the control group (Figure 2). The intervention group also delayed introduction of drink/food other than breast milk, compared with the control group ( $p<$ 0.05 ) (Figure 3). A comparison between 6 and 24 months indicated that the control group increased consumption of 

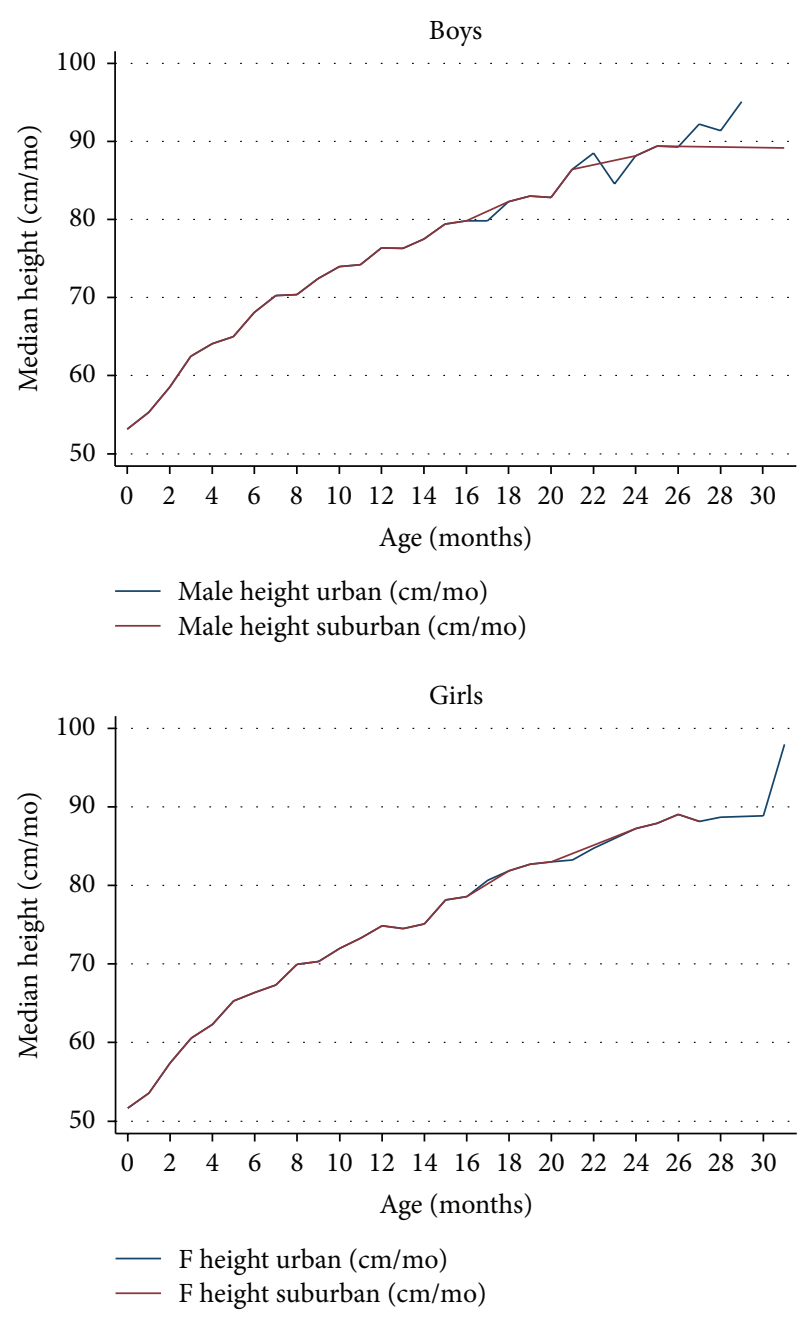

FIGURE 1: Growth trajectory (height) by geographic location for boys and girls.

unsweetened drinks $(p<0.04)$ and of vitamin supplements $(p<0.04)$ relative to the intervention group.

3.4. Child Feeding Practices. The results of the CFQ are shown in Table 2. Parents in the intervention group exerted more dietary restriction on their child $(p<0.01)$ and were more active in monitoring child feeding $(p<0.05)$ than those in the control group. Overall, breastfeeding practice was low. Current breastfeeding rates as reported by mothers in the intervention and control group, respectively, were as follows: $21 \%$ and $18 \%$ at baseline, $23 \%$ and $20 \%$ at 6 months, $22 \%$ and $22 \%$ at 9 months, $21 \%$ and $19 \%$ at 12 months, and $20 \%$ and $20 \%$ at 24 months (final visit). In the intervention group, $49 \%$ of mothers reported ever breastfeeding versus $64 \%$ in the control group. The lower rate of ever breastfeeding reported was primarily driven by the urban intervention site.

3.5. Income Level and Supplemental Nutrition Assistance Program (SNAP). SNAP participation was associated with income level and was substantially higher in urban (65 and
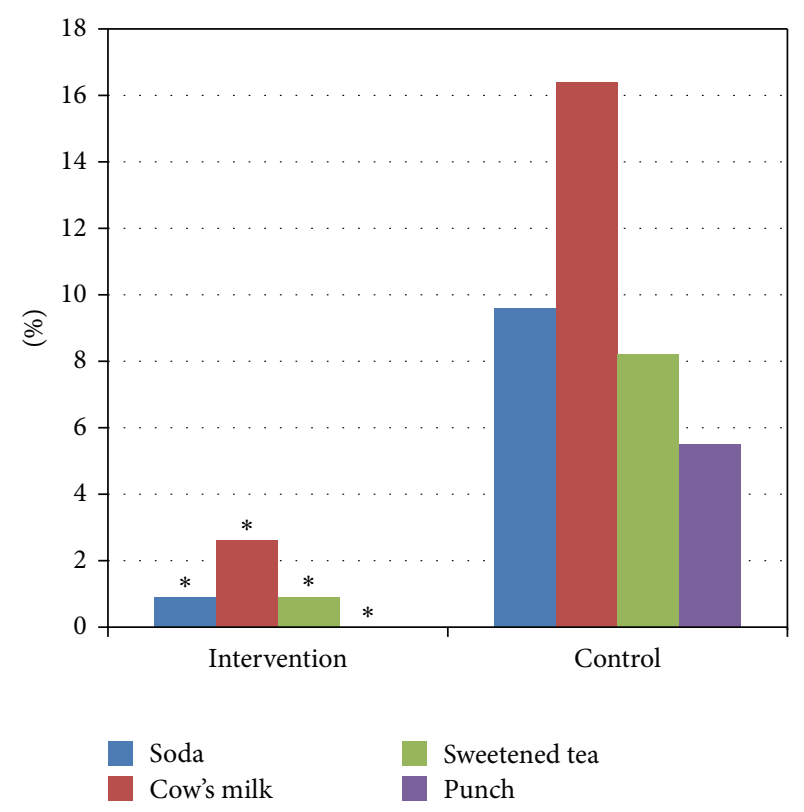

FIGURE 2: Liquids other than breast milk or formula offered to infants. *Soda: $p<0.006$, cow's milk: $p<0.001$, sweetened tea: $p<0.014$, and punch: $p<0.021$.

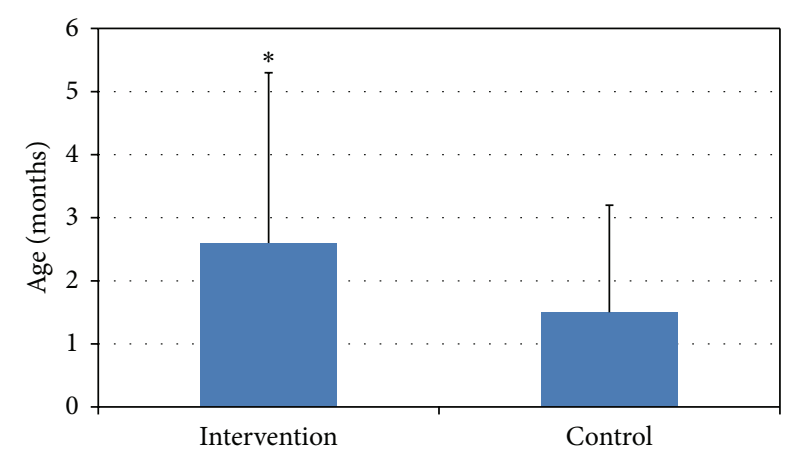

Figure 3: Age of infant at introduction of food/drink other than breast milk. ${ }^{*} p<0.051 . n=82($ control $=37$, intervention $=45)$, considering only caregivers who ever breastfed.

$43 \%)$ than in suburban (6\% in both) clinics, regardless of treatment allocation. Income level was similar in 3 of the 4 clinics: suburban $\mathrm{C}$ and suburban I and urban $\mathrm{C}$. The urban I clinic had $74 \%$ of participants in the lowest income level, compared with $20-30 \%$ in the other three. We evaluated the possible association between SNAP use and study outcomes. The only significant difference was for body weight at 24 months, which was $0.7 \mathrm{~kg}$ higher in SNAP participants $(p<$ $0.01)$.

\section{Discussion}

Our results show that a simple guidance program introduced during routine well-baby visits can positively change several parental dietary practices. For example, parents receiving the intervention provided less soda, sweetened tea, 
TABLE 2: Child Feeding Questionnaire Scores by control and intervention groups at 24 months.

\begin{tabular}{|c|c|c|c|}
\hline & $\begin{array}{l}\text { Control } \\
n=102\end{array}$ & $\begin{array}{c}\text { Intervention } \\
n=84\end{array}$ & $p$ value \\
\hline & $\begin{array}{c}\text { Mean (SD) } \\
95 \% \text { confidence interval }\end{array}$ & $\begin{array}{c}\text { Mean (SD) } \\
\text { 95\% confidence interval }\end{array}$ & $p$ value \\
\hline \multirow{2}{*}{ (1) Perceived feeding responsibility } & $4.45(0.78)$ & $4.50(0.63)$ & \multirow{2}{*}{0.930} \\
\hline & $4.30-4.60$ & $4.37-4.63$ & \\
\hline \multirow{2}{*}{ (2) Perceived parent overweight } & $3.28(0.50)$ & $3.15(0.50)$ & \multirow{2}{*}{0.409} \\
\hline & $3.18-3.38$ & $3.04-3.26$ & \\
\hline \multirow{2}{*}{ (3) Perceived child overweight } & $2.89(0.47)$ & $2.98(0.26)$ & \multirow{2}{*}{0.194} \\
\hline & $2.80-2.98$ & $2.92-3.04$ & \\
\hline \multirow{2}{*}{ (4) Concerns about child overweight } & $2.06(1.20)$ & $2.29(1.36)$ & \multirow{2}{*}{0.329} \\
\hline & $1.83-2.29$ & $2.00-2.58$ & \\
\hline \multirow{2}{*}{ (5) Dietary restriction } & $3.44(0.86)$ & $3.77(0.72)$ & \multirow{2}{*}{0.010} \\
\hline & $3.27-3.61$ & $3.62-3.92$ & \\
\hline \multirow{2}{*}{ (6) Pressure to eat } & $2.68(1.10)$ & $2.72(1.30)$ & \multirow{2}{*}{0.939} \\
\hline & $2.47-2.89$ & $2.44-3.00$ & \\
\hline \multirow{2}{*}{ (7) Monitoring } & $4.13(0.99)$ & $4.41(0.84)$ & \multirow{2}{*}{0.046} \\
\hline & $3.94-4.32$ & $4.23-4.59$ & \\
\hline
\end{tabular}

punch, or cow's milk as complementary fluids for breastfed babies. Juice and sweetened beverage consumption may be associated with obesity and short stature further displacing nutrient-dense foods $[9,10]$. Intervention parents also delayed the introduction of fluids or foods other than breast milk. Early introduction of foods continues to be a concern [11] and may increase the risk of obesity $[12,13]$.

Breastfeeding in our study population was lower than the state of MD average at 6 months (21\% versus $48 \%$ ), but comparable at 12 months (20\% versus $22 \%$ ). For those who ever breastfed, the rate for both the intervention (49\%) and control (64\%) was lower than the rate reported for the state of Maryland (72.6\%). This difference may be due to our small sample size, clearly not representative of the diversity of the state of MD.

There were no differences in BMI between groups at the end of the intervention. However, the intervention group had significantly higher weight and height than the control group at the beginning of the study, and this difference disappeared at around 6 months. We did not adjust for baseline weight and height in the analysis. We used the Student's $t$-test to look at differences between intervention and control for the anthropometric measurements. Because of the sample size, it was important not to make too many adjustments.

Pediatricians and their health care team can greatly influence parental child rearing behaviors, but time constraints may limit opportunities for delivery and tracking of educational messages. The GLB program was designed to be presented in about 5 minutes, focusing on no more than three items at each visit and including a printed brochure as a permanent record of each mini session. As expected implementation was strong during the first year, when wellbaby visits are frequent, and declined in the second year, when many children have only 2 or 3 visits.
We found only three studies on obesity prevention starting at birth [14-16] and a methods paper "as discussed by Karanja et al. [17]." Costom and Shore [14] focused on an individualized feeding approach, including individualized feeding instructions (exclusive breastfeeding and introduction of cow's milk and solid foods) based on the growth pattern of the infant starting at 6 weeks and at 3, 5, 8, 12, 16, and 20 months. Additionally, growth curves of the infant's height and weight were provided to parents to help them visualize their infant's growth; further, misconceptions about a child's weight gain were addressed when necessary. Costom and Shore's approach resulted in reduced adiposity in 182 infants and delayed introduction of foods until 3-4 months of age. In the current study, an approach customized to the infant's development significantly delayed the introduction of food and drink similar to Costom and Shore [14].

Karanja et al. [15] found the combination of a communitywide and family intervention in American Indian/Alaskan tribes attenuated BMI rise in toddlers (24 months old) and increased parents' confidence in reducing sugar-sweetened beverages. Similar to Karanja et al. [15], our data showed the intervention group exhibited greater dietary restriction and offered significantly less sweetened beverages to infants compared to the control group. However, this did not translate to changes in BMI. We may not have seen changes in BMI because our study population had a normal BMI. Karanja et al. found an attenuated rise in BMI in a population (American Indian) of infants that tend to have rapid growth from 6 to 9 months in age compared to WHO standards. On the other hand, Paul et al. [16] found infants (with a normal weight-for-length) had a lower weight-for-length percentile at 1 year after parents received two home visits focused on non-hunger-related fussiness, sleep duration, introduction of solid foods, and incorporation of healthy foods. According 
to the Pediatric Nutrition Surveillance System, $8.0 \%$ of 011-month-old infants and $12.3 \%$ of $24-35$-month-old infants are considered obese [18]. The low prevalence of obesity in our sample may be due to the small sample size, further contributing to no effect of BMI.

One of our four study sites in the intervention group exhibited some of the demographic characteristics associated with low-income, inner city populations: higher unemployment, lower income, and more use of SNAP and WIC services. Because the pattern for income level mimicked the pattern for SNAP participation, we were interested in whether income level and SNAP participation influenced the various outcomes related to adiposity. Interestingly, babies whose families participated in SNAP had a final body weight $0.7 \mathrm{~kg}$ greater than those babies whose families did not participate in SNAP, the urban intervention site largely driving this finding. However, there was no difference in babies' BMI between families participating in SNAP versus nonparticipants. A recent study found, among low-income adults, that SNAP participation has been found to be associated with greater adiposity, BMI, waist circumference, and other metabolic risk factors [19]. Additionally, the diet quality of adult SNAP participants was lower than income-eligible nonparticipants [20]. Gibson 2006 found long-term food stamp participation (currently SNAP) to be positively associated with overweight in girls aged 4.5-11.5 years and obesity in mothers [21]. However, in preschool age children, BMI percentile did not differ between SNAP and non-SNAP participants although the prevalence of obesity was increased in SNAP participants compared to eligible nonparticipants but again were not statistically different [22]. Although our finding is somewhat controversial one must recognize the complexity of this outcome. Those who lived in the urban intervention site did not have access to adequate grocery stores and healthy food options, mainly purchasing food items from corner convenience stores where options are limited; thus, multiple and complex reasons may be contributing to the greater final body weight in those who participate in SNAP. When designing future interventions, one must take into consideration SNAP participation, urban dwelling, and socioeconomic status and customize the program appropriately. Further, because the physicians can have a major impact on parents' behavior, it is imperative that the physicians receive the most appropriate training for their clientele. Finally, it would be important to collect information on maternal anthropometry, medical history of the child, and pregnancy smoking in future interventions.

\section{Conclusion}

In summary, our intervention was able to significantly improve several parental behaviors related to child feeding and increased parental sense of responsibility toward their child's eating behaviors. While the small number of clinics included in the study resulted in an intervention group with more adverse socioeconomic indicators than the control group, there were no differences in growth trajectory or in body size indices between the groups at the end of the followup period. Education and motivation provided by health care providers may be an important component of a multilevel approach to early obesity prevention.

\section{Abbreviations}

$\begin{array}{ll}\text { ANOVA: Analysis of variance } \\ \text { BAZ: } & \text { BMI-for-age } z \text {-score } \\ \text { BMI: } & \text { Body mass index }\end{array}$

CFQ: Child Feeding Questionnaire

F: $\quad$ Female

FFQ: Food Frequency Questionnaire

GLB: Growing Leaps and Bounds

$\mathrm{I} \quad$ Intervention group

JHCP: Johns Hopkins Community Physicians

M: $\quad$ Male

MD: State of Maryland

SNAP: Supplemental Nutrition Assistance Program

WHO: World Health Organization

WIC: Women, Infants, and Children

WHZ: Weight-for-length $z$-score.

\section{Conflict of Interests}

The authors have no conflict of interests to disclose. The authors have no financial relationships relevant to this paper to disclose.

\section{Acknowledgment}

This study was funded by a competitive grant from the Dannon Institute (USA).

\section{References}

[1] C. L. Ogden, M. D. Carroll, B. K. Kit, and K. M. Flegal, "Prevalence of obesity in the United States, 2009-2010," NCHS Data Brief, no. 82, pp. 1-8, 2012.

[2] C. L. Ogden, M. D. Carroll, B. K. Kit, and K. M. Flegal, "Prevalence of obesity and trends in body mass index among US children and adolescents, 1999-2010," The Journal of the American Medical Association, vol. 307, no. 5, pp. 483-490, 2012.

[3] A. M. Magarey, L. A. Daniels, T. J. Boulton, and R. A. Cockington, "Predicting obesity in early adulthood from childhood and parental obesity," International Journal of Obesity and Related Metabolic Disorders, vol. 27, no. 4, pp. 505-513, 2003.

[4] J. Baird, D. Fisher, P. Lucas, J. Kleijnen, H. Roberts, and C. Law, "Being big or growing fast: systematic review of size and growth in infancy and later obesity," British Medical Journal, vol. 331, no. 7522, pp. 929-931, 2005.

[5] B. A. Dennison, L. S. Edmunds, H. H. Stratton, and R. M. Pruzek, "Rapid infant weight gain predicts childhood overweight," Obesity, vol. 14, no. 3, pp. 491-499, 2006.

[6] P. O. A. Monteiro and C. G. Victora, "Rapid growth in infancy and childhood and obesity in later life-a systematic review," Obesity Reviews, vol. 6, no. 2, pp. 143-154, 2005. 
[7] University of Maryland, School of Medicine, Division of Growth and Nutrition, TOPS-Publications, 2014, http://medschool.umaryland.edu/growth/tops_pubs.asp.

[8] S. Sharma, X. Cao, C. Arcan et al., "Assessment of dietary intake in an inner-city African American population and development of a quantitative food frequency questionnaire to highlight foods and nutrients for a nutritional invention," International Journal of Food Sciences and Nutrition, vol. 60, no. 5, pp. 155$167,2009$.

[9] B. A. Dennison, H. L. Rockwell, and S. L. Baker, "Excess fruit juice consumption by preschool-aged children is associated with short stature and obesity," Pediatrics, vol. 99, no. 1, pp. 1522, 1997.

[10] M. M. Smith and F. Lifshitz, "Excess fruit juice consumption as a contributing factor in nonorganic failure to thrive," Pediatrics, vol. 93, no. 3, pp. 438-443, 1994.

[11] H. B. Clayton, R. Li, C. G. Perrine, and K. S. Scanlon, "Prevalence and reasons for introducing infants early to solid foods: variations by milk feeding type," Pediatrics, vol. 131, no. 4, pp. el108-e1114, 2013.

[12] M. S. Kramer, R. G. Barr, D. G. Leduc, C. Boisjoly, L. McVeyWhite, and I. B. Pless, "Determinants of weight and adiposity in the first year of life," The Journal of Pediatrics, vol. 106, no. 1, pp. $10-14,1985$

[13] J. L. Baker, K. F. Michaelsen, K. M. Rasmussen, and T. I. A. Sørensen, "Maternal prepregnant body mass index, duration of breastfeeding, and timing of complementary food introduction are associated with infant weight gain," American Journal of Clinical Nutrition, vol. 80, no. 6, pp. 1579-1588, 2004.

[14] B. H. Costom and D. Shore, "Effect of a comprehensive nutritional program on the growth and ponderosity of infants," Clinical Pediatrics, vol. 22, no. 2, pp. 105-111, 1983.

[15] N. Karanja, T. Lutz, C. Ritenbaugh et al., “The TOTS community intervention to prevent overweight in American Indian toddlers beginning at birth: a feasibility and efficacy study," Journal of Community Health, vol. 35, no. 6, pp. 667-675, 2010.

[16] I. M. Paul, J. S. Savage, S. L. Anzman et al., "Preventing obesity during infancy: a pilot study," Obesity, vol. 19, no. 2, pp. 353-361, 2011.

[17] N. Karanja, M. Aickin, T. Lutz et al., "A community-based intervention to prevent obesity beginning at birth among American Indian children: study design and rationale for the PTOTS study," The Journal of Primary Prevention, vol. 33, no. 4, pp. 161-174, 2012.

[18] K. Dalenius, E. Borland, B. Smith, B. Polhamus, and L. Grummer-Strawn, Pediatric Nutrition Surveillance 2010 Report, US Department of Health and Human Services, Centers for Disease Control and Prevention, Atlanta, Ga, USA, 2012.

[19] C. W. Leung, W. C. Willett, and E. L. Ding, "Low-income supplemental nutrition assistance program participation is related to adiposity and metabolic risk factors," American Journal of Clinical Nutrition, vol. 95, no. 1, pp. 17-24, 2012.

[20] C. W. Leung, E. L. Ding, P. J. Catalano, E. Villamor, E. B. Rimm, and W. C. Willett, "Dietary intake and dietary quality of low-income adults in the Supplemental Nutrition Assistance Program," The American Journal of Clinical Nutrition, vol. 96, no. 5, pp. 977-988, 2012.

[21] D. Gibson, "Long-term food stamp program participation is positively related to simultaneous overweight in young daughters and obesity in mothers," Journal of Nutrition, vol. 136, no. 4, pp. 1081-1085, 2006.
[22] S. Simmons, J. L. Alexander, H. Ewing, and S. Whetzel, "SNAP participation in preschool-aged children and prevalence of overweight and obesity," Journal of School Health, vol. 82, no. 12, pp. 548-552, 2012. 


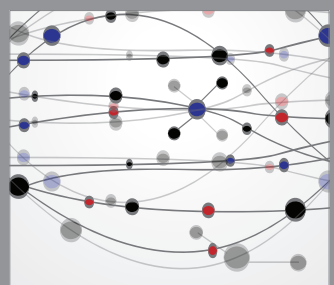

The Scientific World Journal
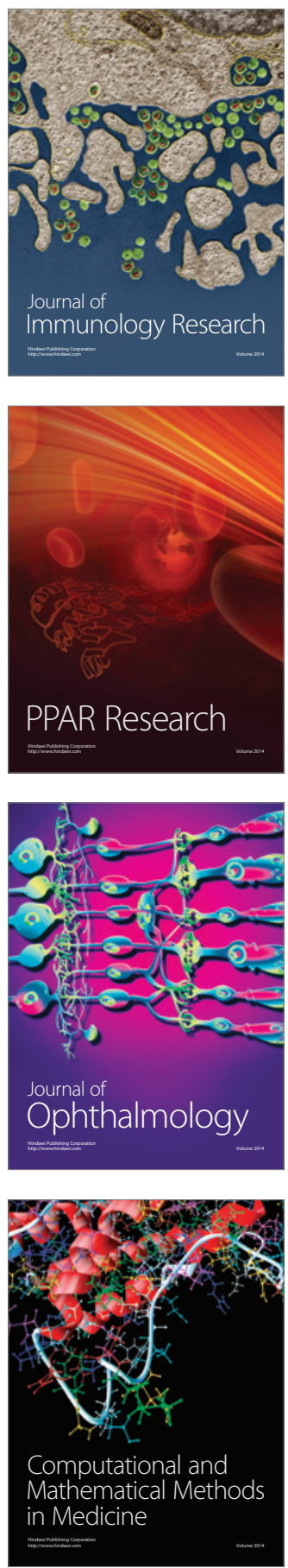

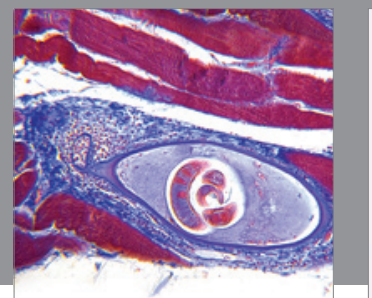

Gastroenterology

Research and Practice
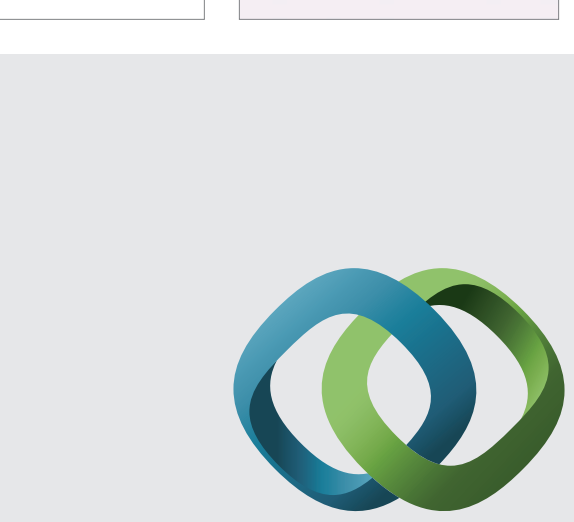

\section{Hindawi}

Submit your manuscripts at

http://www.hindawi.com
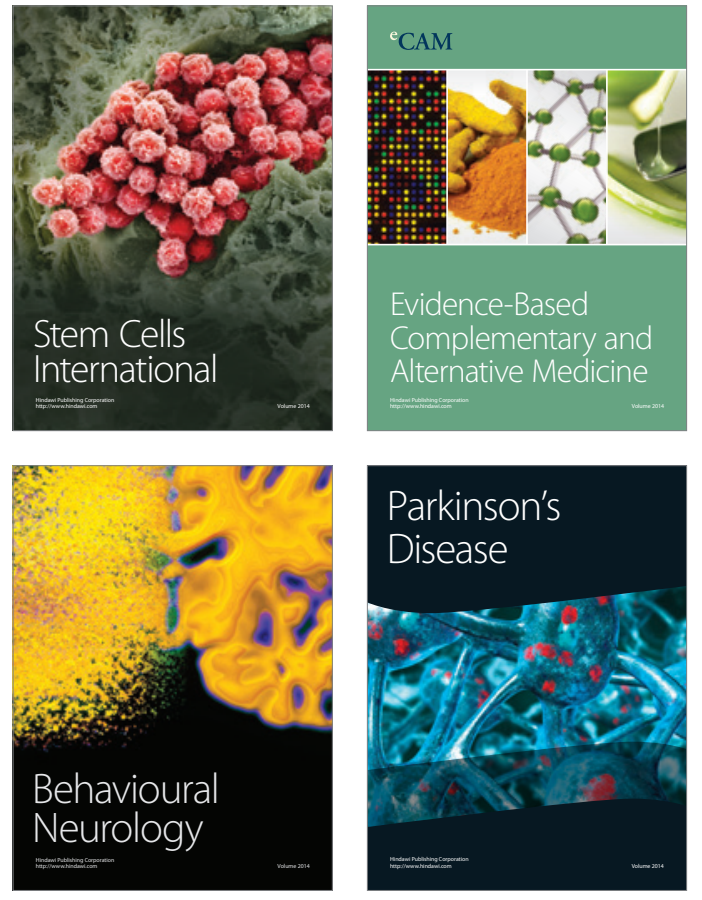
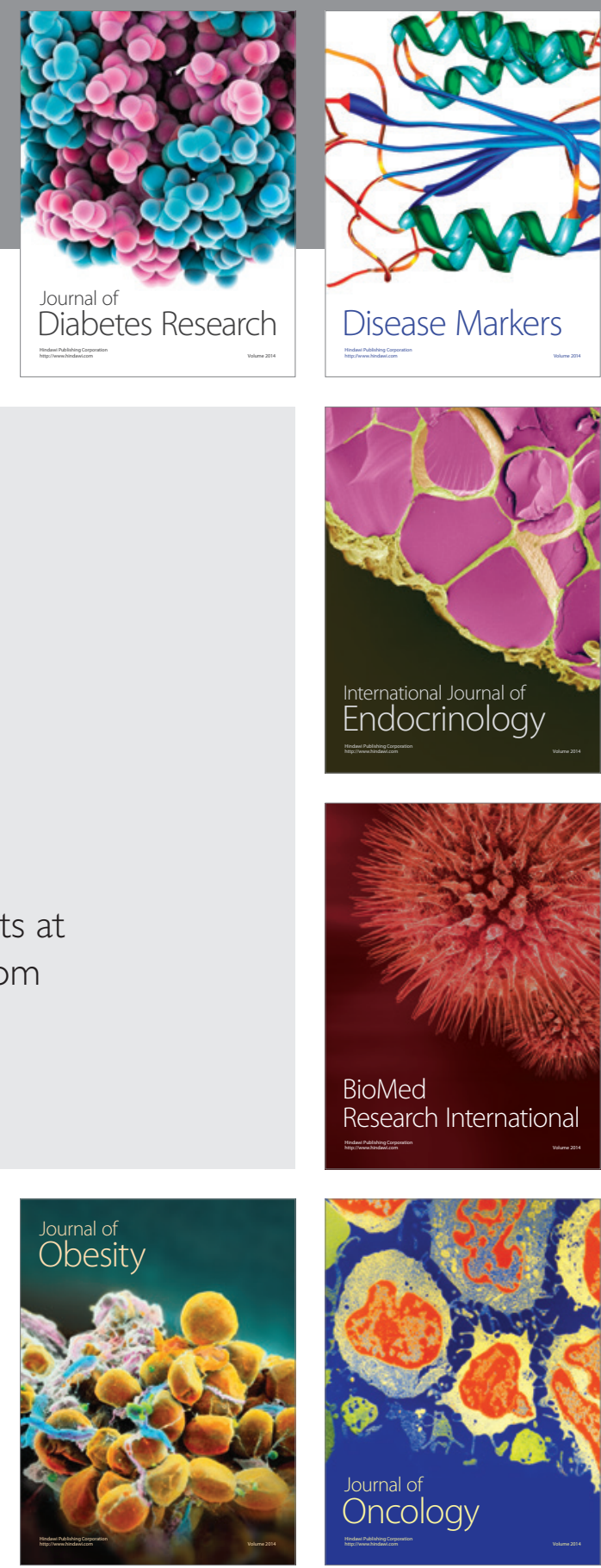

Disease Markers
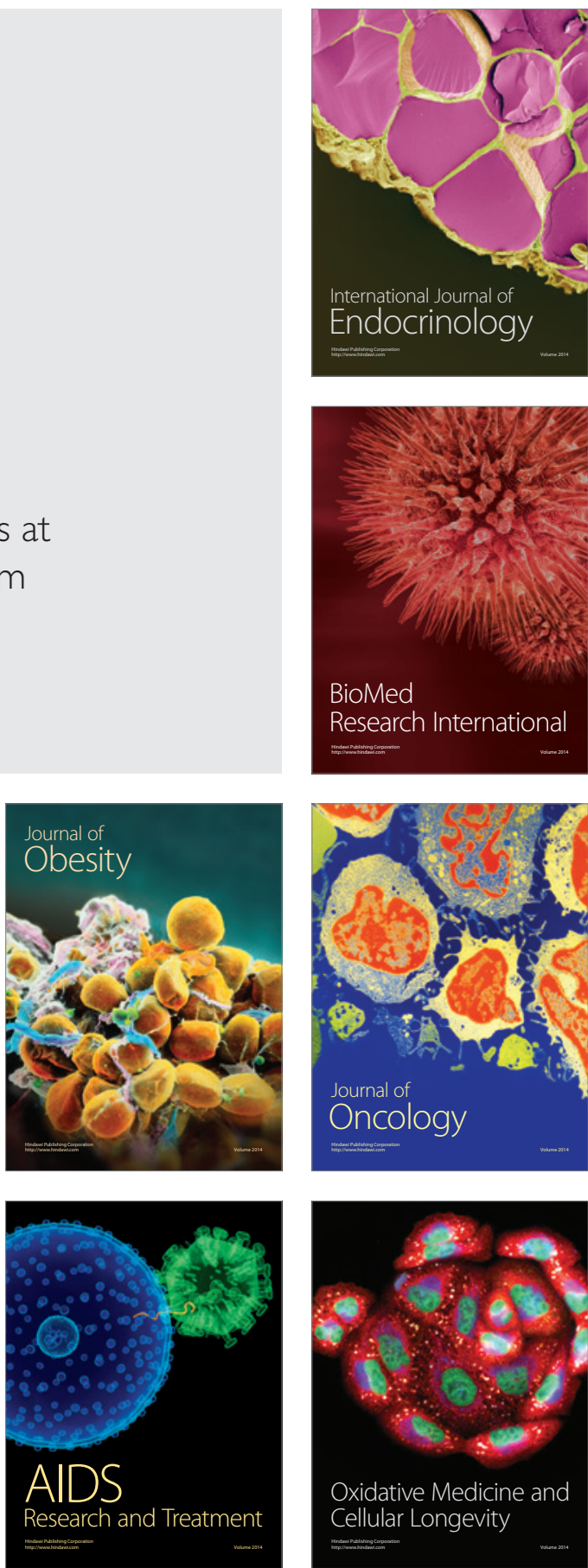